\title{
Distribuição do compartimento arbóreo em gradiente de relevo e solos na encosta Meridional da Serra Geral, RS
}

\author{
Tree distribution along a relief and soil gradient on the Southern of Serra Geral, \\ Rio Grande do Sul
}

\author{
Marcelo Callegari Scipioni' ${ }^{\mathrm{I}}$ Solon Jonas Longhi ${ }^{\mathrm{II}}$ Dalvan José Reinert ${ }^{\mathrm{III}}$ \\ Maristela Machado Araújo ${ }^{\text {II }}$ Fabrício de Araújo Pedron ${ }^{\text {III }}$
}

\section{RESUMO}

O presente trabalho foi realizado em fragmento de Floresta Estacional Decidual (29³2'27”S e 5348’35”W), na Reserva Biológica do Ibicuí-Mirim, localizada no Município de São Martinho da Serra, Estado do Rio Grande do Sul, Brasil, com o objetivo de avaliar as correlações existentes entre a composição florística das espécies arbóreas sobre diferentes condições topográficas e pedológicas sem influência fluvial. Foram instaladas 28 parcelas de $20 \times 20 \mathrm{~m}$ para amostrar todos os indivíduos com circunferência à altura do peito $(C A P)=30 \mathrm{~cm}$. Nas parcelas, foram coletadas amostras superficiais de solos (0-20cm) para análise química e granulométrica, além de informações morfológicas dos perfis de solo e topográficas do terreno. Foram registrados 734 indivíduos arbóreos, nos quais, por meio da Análise de Correspondência Canônica (CCA), foi verificada a ordenação ambiental das principais espécies no gradiente topográfico pelas variáveis ambientais de declividade do terreno, cota altimétrica, CTC efetiva, relação $\mathrm{Ca} / \mathrm{Mg}$ e grau de desenvolvimento do solo. Essas variáveis caracterizaram as diferenças entre as classes de Neossolos do estudo que apresentaram pouco reflexo na distribuição das espécies no gradiente topográfico.

Palavras-chave: relação vegetação-solo, Neossolos, Trichillia claussenii.

\section{ABSTRACT}

This research was performed in a deciduous forest

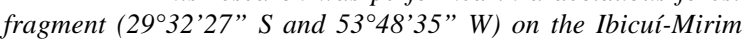
biological reserve in the municipality of São Martinho da Serra, in the state of Rio Grande do Sul, Brazil. The aim was to evaluate the correlations between the floristic compositions of

\begin{abstract}
tree species growing in different topographical and pedological conditions without river influences. Twenty-eight plots measuring $20 \times 20 \mathrm{~m}$ were established to test all individuals with $=30 \mathrm{~cm}$ circumference at breast height $(\mathrm{CBH})$. Superficial soil samples $(0-20 \mathrm{~cm})$ were collected for chemical and granulometric analysis. Also, the morphological characteristics of the soils and the topographical information of the terrain were noted. A Canonical Correspondence Analysis (CCA) was conducted on the 734 individual trees and shrubs that were registered to determine the environmental classification of the species found on the topographical gradient using variables such as terrain declivity, altitude, effective $\mathrm{CEC}, \mathrm{Ca} / \mathrm{Mg}$ relations, and soil development. These environmental variables characterized the differences between the classes of Neosoils in this study that had little influence on the distribution of species on this topographical gradient.
\end{abstract}

Key words: soil-vegetation relationship, Leptosols, Trichillia claussenii.

\section{INTRODUÇÃO}

As florestas de encosta da borda erodida do planalto sul-brasileiro meridional são formadas sobre um relevo acidentado, conhecido vulgarmente como Serra Geral, cortando ao meio de Leste a Oeste o território do Estado do Rio Grande do Sul (RS), e florestas de regiões montanhosas. Essas florestas são vegetações de grande importância para a conservação do solo e para a manutenção e preservação das

IServiço Florestal Brasileiro, Cenaflor, Centro Nacional de Apoio ao Manejo Florestal, 70818-900, Brasília, DF, Brasil. E-mail: marcelo.scipioni@gmail.com. Autor para correspondência.

"Programa de Pós-graduação em Engenharia Florestal, Departamento de Ciências Florestais, Universidade Federal de Santa Maria (UFSM), Santa Maria, RS, Brasil.

IIIPrograma de Pós-graduação em Ciência do Solo, Departamento de Solos, UFSM, Santa Maria, RS, Brasil. 
nascentes, fornecendo água de qualidade e quantidade para os cursos fluviais, de modo a proporcionar condições para sobrevivência da biodiversidade regional (OLIVEIRA-FILHO et al., 2004, OLIVEIRA et al., 2005), além de auxiliar nas estabilidades das encostas.

O relevo das escarpas da Serra Geral é formado por sequências espessas de rochas vulcânicas de predomínio básico, mas podendo conter termos ácidos nas porções superiores dos derrames. As cotas altimétricas decrescem na porção Oeste em direção à bacia sedimentar do Paraná em decorrência da aproximação da drenagem do rio Uruguai, onde ficam entre 300 e 400m de altitude. A forma do relevo apresenta-se ora em "V" aberto, ora em "V" fechado por patamares verticais formados por sulcos e vales dos rios e riachos que deságuam em direção da unidade de relevo da depressão periférica da bacia do Paraná (HERRMANN \& ROSA, 1990). Os solos da região são predominantemente pouco desenvolvidos, rasos, possuindo o horizonte A diretamente assentado sobre a rocha ou sobre o horizonte $\mathrm{C}$ ou camada $\mathrm{Cr}$, geralmente com muito material de rocha em decomposição (saprólito), nesse caso, chamados de Neossolos (PEDRON et al., 2009). Quando apresentam um horizonte B em estágio inicial de formação, são chamados de Cambissolos. A drenagem dos solos apresenta-se de bem a acentuadamente drenado. Os solos possuem alta fertilidade natural em razão dos altos valores de soma e saturação de bases, além de teores baixos de alumínio trocável (STRECK et al., 2002).

A Reserva Biológica do Ibicuí-Mirim (RBMI) localizada na Serra Geral, no centro do Estado do Rio Grande do Sul (RS), foi criada em 1982 pelo decreto estadual nº 30.930, possuindo uma área de 598,48ha. Os subsídios para criação basearam-se nos estudos de flora e fauna realizados pela Fundação Zoobotânica do RS e pelo apoio dado pela Companhia Riograndense de Saneamento. O objetivo da criação da reserva foi o de preservar o curso superior do rio Ibicuí-Mirim próximo das suas nascentes e a vegetação remanescente (OLIVEIRA, 1991). A vegetação, segundo OLIVEIRA-FILHO et al. (2006), pertence à região fitogeográfica de Floresta Estacional Decidual submontana.

Dessa forma, este estudo tem o objetivo caracterizar o gradiente pedológico e topográfico da encosta sem influência fluvial e suas principais variáveis ambientais, e constatar a hipótese da existência preferencial de ocorrência das espécies arbóreas nesses gradientes, na RBIM, no interior do rebordo meridional da Serra Geral, e conhecer o comportamento das principais espécies arbóreas de maior abundância.

\section{MATERIAL E MÉTODOS}

O levantamento das espécies arbóreas foi realizado em parcelas de $400 \mathrm{~m}^{2}$ (20x20m) sem influência fluvial, onde foram amostrados todos os indivíduos, com circunferência à altura do peito $(\mathrm{CAP})=30 \mathrm{~cm}$. O total de unidades amostrais utilizadas foi de 28, totalizando $11.200 \mathrm{~m} 2$ (1,12ha). As parcelas foram distribuídas sistematicamente em dois gradientes de topografia (lado Ae B), com parcelas distanciadas entre si a 40m, em linhas amostrais instaladas da base até o topo do morro, conforme figura 1.

Para compor os dados da matriz do estudo, foram coletadas informações do ambiente de cada parcela, referentes às variáveis de solo e relevo. As informações referentes das variáveis solos foram coletadas de amostras compostas superficiais, na profundidade de $0-20 \mathrm{~cm}$, com a finalidade de realizar análises químicas de macro e micronutrientes e granulométricas (\% de areia, silte e argila). A análise granulométrica foi desenvolvida pelo método da pipeta, conforme os procedimentos sugeridos pela EMBRAPA (1997). A classificação do solo foi realizada conforme o Sistema Brasileiro de Classificação de Solos (EMBRAPA, 2006), nas parcelas centrais da base até o topo do morro, em ambos os lados (A e B), com abertura de trincheiras para descrição morfológica dos perfis de solo, conforme metodologia de SANTOS et al. (2005) e adaptações de PEDRON et al. (2009). No presente estudo, as classes de solo também foram consideradas como variáveis. Estas foram expressas como variável ordinal, com peso maior para os solos com menor grau de desenvolvimento (profundidade efetiva), expressos com os seguintes pesos: 1 - Neossolos Regolíticos; 2 - Neossolos Litólicos 1; e 3 - Neossolos Litólicos 2. Nas classes de solos, foram realizadas análises de variâncias para as variáveis topográficas, químicas e granulométricas dos solos, seguidas por testes de Tukey, para analisar as diferenças entre estas.

As variáveis ambientais topográficas do terreno observadas foram: declividade média e cota altimétrica. As declividades foram medidas com hipsômetro de Blume Leiss, com leitura em graus. Estas foram medidas nas duas faces paralelas de maior declividade das parcelas. A partir da média dessas medidas, foi obtida a variável declividade média. A variável cota altimétrica foi medida no centro das parcelas com a utilização de um altímetro.

Para análise de ordenação das variáveis ambientais e da vegetação, foi utilizada a análise de correspondência canônica (CCA) (TER BRAAK, 1987), pelo programa computacional PC-ORD for Windows, versão 5.0 (MCCUNE \& MEFFORD, 2006). A matriz de 

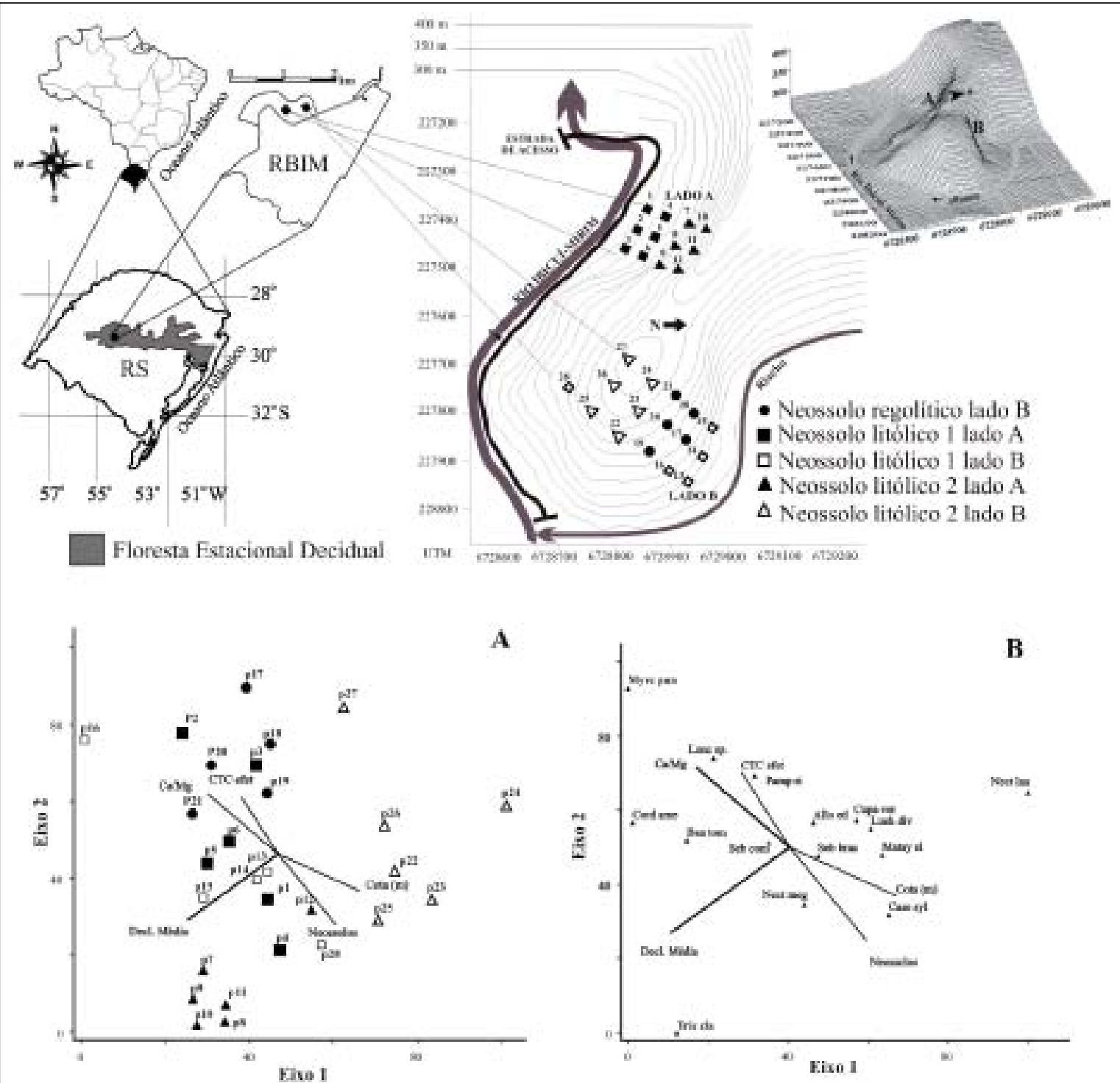

A

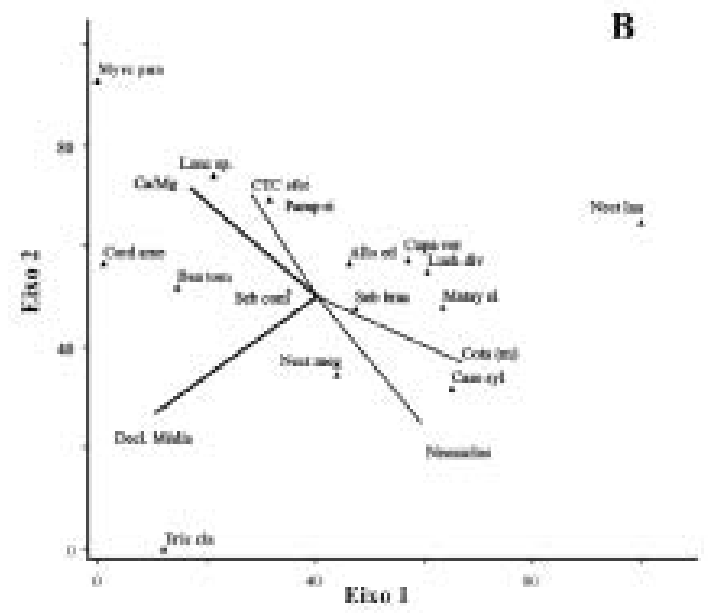

Figura 1 - Aspecto geral das áreas de estudo, localização das parcelas na face sudoeste (Lado A) e nordeste (Lado B), com suas respectivas classes de solo, na Reserva Biológica do Ibicuí-Mirim (RBIM), São Martinho da Serra, RS. Análise de correspondência canônica: diagrama de ordenação das parcelas (A) e espécies (B) e suas correlações com as principais variáveis ambientais.

composição das espécies da análise foi constituída por número de indivíduos que apresentavam 10 ou mais exemplares na amostra total, ficando a matriz de dados com 15 espécies e 28 parcelas. O número de espécies a serem incluídas na matriz varia na abundância (densidade) das espécies, e as espécies menos abundantes apresentam menor contribuição ou quase nada na ordenação dos dados. Assim, estas são eliminadas, conforme SOUZA et al. (2003). De acordo com as recomendações de TER BRAAK (1995), os valores da abundância das espécies foram transformados pela expressão $\log _{10}(\mathrm{a}+1)$, para compensar desvios causados por valores elevados de algumas espécies. Com a realização de uma CCA preliminar, eliminaram-se as variáveis que produziram correlações baixas $(<0,4)$ ou redundantes. A CCA final foi processada com cinco variáveis fortemente correlacionadas com os eixos de ordenação e representativas no gradiente (declividade média, cota altimétrica, $\mathrm{Ca} / \mathrm{Mg}$, CTC efetiva e grau de desenvolvimento do solo). Para analisar a correlação das espécies e variáveis ambientais principais, foi realizada uma correlação de Spearman. 


\section{RESULTADOS E DISCUSSÃO}

Foram caracterizadas três classes de solos, sendo os Neossolos Litólicos diferenciados pelo grau de desenvolvimento dos horizontes: em Neossolos Litólicos Eutróficos fragmentários 1, Neossolos Litólicos Eutróficos fragmentários 2 e Neossolos Regolíticos Eutróficos típicos. Os Neossolos Litólicos 1 apresentaram maior desenvolvimento no horizonte A, com presença de solo misturado com saprolitos, caracterizando maior grau de desenvolvimento em comparação aos Neossolos Litólicos 2. Entretanto, os Neossolos Litólicos 2 apresentaram um horizonte A formado por alta porcentagem de fragmentos grosseiros (rocha e saprolito) de maior grau de resistência mecânica ao corte com a pá. Os Neossolos Litólicos 1 foram representados pelas parcelas localizadas nas áreas inferiores e da meia encosta do relevo, constituídas pelas parcelas de 1 a 6 no lado A, 13 a 16 e pela parcela 28 no lado $\mathrm{B}$, conforme figura 1 . Os Neossolos Litólicos 2 foram localizados nas partes altas do relevo, sobre diferentes condições de declividade, sendo que nos locais de alta declividade, foram representados pelas parcelas 7 a 12 no lado A, e nas áreas de menor declividade pelas parcelas de 22 a 27 no lado B. Os Neossolos Regolíticos apresentaram profundidade efetiva maior, com valores entre $0-75 \mathrm{~cm}$ + , caracterizada pela presença dos horizontes e das camadas A, ACr e Cr, formados por saprólitos de baixa e alta resistência física quando submetidos ao corte com a pá. Essa última classe de solo foi levantada nas parcelas de 17 a 21, no lado B do morro, com declividade média de $29,6 \pm 5,47^{\circ}$ (Figura 1 ).

A variabilidade morfológica dos Neossolos, resultante da conformação geomorfológica do terreno, promove a ocorrência de Neossolos Litólicos e Neossolos Regolíticos em pequenas áreas, formando associações de solos e, muitas vezes, até mesmo complexos de solos (PEDRON, 2007). A diferença entre essas classes de solos é a profundidade do contato lítico e a presença de camada saprolítica em profundidade superior a $50 \mathrm{~cm}$ da superfície do solo (EMBRAPA, 2006). Assim, a declividade do terreno no gradiente expôs de diversas formas as condições de erosão dos solos rochosos, aumentando o transporte dos materiais de origem do substrato e condicionando o maior grau de pedregosidade da superfície, a classe de drenagem e, consequentemente, o grau de desenvolvimento do solo (profundidade). Dessa forma, esta foi a principal variável do trabalho, em decorrência da homogeneidade dos Neossolos no gradiente, em razão dos fatores químicos e texturais, que apresentam variação não significativa, por comparação de média no teste de Tukey, com exceção do Mg, que apresentou valores médios mais elevados nos Neossolos Regolíticos em comparação com os Neossolos Litólicos 1 e 2. Mais detalhes dessa análise podem ser encontrados em SCIPIONI (2008).

Os Neossolos Regolíticos devem apresentar menor resistência à penetração de raízes em razão da presença de material alterado e, frequentemente, mais fraturado (SCHAFER et al., 1979; LIETZKE \& WEBER, 1981; PEDRON et al., 2009). Em relação à composição química desses solos, ambas as classes são condicionadas pela rocha de origem, pelo clima, pela drenagem e pela situação topográfica (PEDRON, 2007). Considerando-se a homogeneidade nessas condições ambientais, é natural que os Neossolos Regolíticos apresentem teores de elementos trocáveis mais elevados que os Litólicos em razão da sua condição de intemperismo, em que maior porcentagem do material já se encontra apta a fornecer nutrientes, ao mesmo tempo em que a fração saprolítica serve de fonte destes.

Na área do estudo, foram amostrados 734 indivíduos de espécies arbóreo-arbustivos, distribuídos em 28 famílias, 50 gêneros e 60 espécies. Mais detalhes sobre a composição florística, fitossociológica e ambiental da área podem ser consultados em SCIPIONI (2008). Os autovalores da CCA da distribuição das espécies, acumulados nos dois primeiros eixos de ordenação, foram baixos: 0,19 (eixo 1) e 0,13 (eixo 2), caracterizando um gradiente curto, com distribuição das espécies por todo o gradiente ambiental e considerando-se que, para algumas espécies, houve variação apenas da abundância relativa. O eixo 1 explicou 15,1\% da variância, enquanto que o eixo 2 correspondeu a 9,8\% da variância, tendo como variância acumulada explicada 24,9\%, indicando ruído ou variância remanescente não explicada, com predominância da variação nas abundâncias das espécies no gradiente e sem ocorrência pontual de espécies na área. O teste de permutação de Monte Carlo indicou baixa correlação entre a abundância das espécies e as variáveis ambientais nos eixos de ordenação $(P=0,10)$, em decorrência, provavelmente, da condição química e textural, com pouca variabilidade no gradiente topográfico e com isso uma única classe de solo predomina no gradiente. As variáveis ambientais amostradas que apresentaram maior correlação em ordem decrescente, no primeiro eixo, foram: declividade média, cota altimétrica e relação $\mathrm{Ca} / \mathrm{Mg}$. Para o segundo eixo, a maior correlação em ordem decrescente foi a classe de solo, com menor destaque para a capacidade de troca de cátions efetiva (CTC efet.), conforme tabela 1.

O gráfico de ordenação (Figura 1) apresentou de forma distinta a distribuição das parcelas 
Tabela 1 - Análise de correspondência canônica: coeficientes canônicos e correlações internas nos primeiros eixos de ordenação e matriz de correlação ponderada entre as variáveis ambientais utilizadas na análise. Coeficientes de correlação de Spearman e sua significância (p) entre a abundância das espécies arbóreas que apresentaram correlação com pelo menos uma variável ambiental utilizada na CCA.

\begin{tabular}{|c|c|c|c|c|c|c|}
\hline \multirow{2}{*}{ Variáveis ambientais } & \multicolumn{2}{|c|}{ Correlações ambientais } & \multirow{2}{*}{ CTC efetiva } & \multirow{2}{*}{$\mathrm{Ca} / \mathrm{Mg}$} & \multirow{2}{*}{ Decliv. Média } & \multirow{2}{*}{ Cota (m) } \\
\hline & Eixo 1 & Eixo 2 & & & & \\
\hline$\overline{\text { CTC efetiva }}$ & 0,251 & 0,370 & - & & & \\
\hline $\mathrm{Ca} / \mathrm{Mg}$ & $-0,480$ & 0,396 & 0,711 & - & & \\
\hline Declividade Média & $-0,612$ & $-0,425$ & $-0,063$ & $-0,044$ & - & \\
\hline Cota (m) & 0,545 & $-0,240$ & $-0,291$ & $-0,528$ & $-0,315$ & - \\
\hline Neossolos & 0,392 & $-0,457$ & $-0,297$ & $-0,227$ & $-0,257$ & 0,703 \\
\hline Espécies & Decliv. média & Cota & & & $\mathrm{Ca} / \mathrm{Mg}$ & CTC \\
\hline Trichilia claussenii & $0,594 *$ & $0,041 \mathrm{~ns}$ & & & $-0,03 \mathrm{~ns}$ & $-0,128 n s$ \\
\hline Cordia americana & $0,341 \mathrm{~ns}$ & $-0,409 *$ & & & $0,370 \mathrm{~ns}$ & $0,225 \mathrm{~ns}$ \\
\hline Myrcianthes pungens & $0,008 \mathrm{~ns}$ & $-0,289 n s$ & & & $0,256 \mathrm{~ns}$ & $0,373 n s$ \\
\hline Lonchocarpus sp. & $-0,024 n s$ & $-0,383^{*}$ & & & $0,391^{*}$ & $0,235 \mathrm{~ns}$ \\
\hline Casearia sylvestris & $-0,247 \mathrm{~ns}$ & $0,472 *$ & & & $-0,159 \mathrm{~ns}$ & $0,074 \mathrm{~ns}$ \\
\hline Nectandra lanceolata & $-0,604 *$ & $0,601^{*}$ & & & $-0,242 \mathrm{~ns}$ & $-0,123 n s$ \\
\hline Cupania vernalis & $-0,615^{*}$ & $0,481 *$ & & & $-0,244 \mathrm{~ns}$ & $0,053 \mathrm{~ns}$ \\
\hline
\end{tabular}

${ }^{*} P<0,05$; ns $=$ não significativo. Decliv. $=$ declividade.

nos eixos de ordenação, em relação ao gradiente ambiental. No primeiro eixo, as parcelas de Neossolos Litólicos 2, na face A do morro (P7, P8, P9, P10, P11 e $\mathrm{P} 12)$, apresentaram elevada correlação com os altos valores de declividade do terreno $\left(36,7 \pm 5,69^{\circ}\right)$, enquanto na face $B$, na mesma classe de solo, as parcelas (P22, P23, P24, P25 e P26) correlacionaram com os maiores valores de cota altimétrica, em relevo de menor declividade $\left(14,8 \pm 6,58^{\circ}\right)$. Os Neossolos Litólicos 1 apresentaram ampla distribuição nos eixos de correlação em decorrência das diferentes posições ocupadas no relevo, onde variaram desde a parte inferior da encosta até a meia encosta superior, com diferentes níveis de declividade.

Os Neossolos Regolíticos tiveram maior correlação no eixo 2, com a relação $\mathrm{Ca} / \mathrm{Mg}$ e CTC, e relação negativa com declividade e grau de desenvolvimento dos Neossolos (parcelas 17, 18, 19, 20 e 21). Isso se deve ao maior desenvolvimento dessa classe de solo em comparação com os Neossolos Litólicos, fazendo com que estes tivessem maiores teores de $\mathrm{Ca}$ e, consequentemente, maior relação Cálcio/Magnésio e maior capacidade de troca de cátions. Além da forma de disposição no relevo das parcelas dos Neossolos Regolíticos localizadas sobre platôs com baixa declividade e maior retenção de água no perfil, o que ocasiona um processo mais intenso do intemperismo químico no solo e, desse modo, possuem um horizonte A com maior desenvolvimento em relação aos solos Litólicos.
As espécies de maior abundância utilizadas no gráfico de ordenação (CCA) foram 15: Trichilia claussenii (Tric clau), Cordia americana (Cord ame), Banara tomentosa (Ban tom), Sebastiania commersoniana (Seb com), Myrcianthes pungens (Myrc pung), Lonchocarpus sp. (Lonc sp.), Nectandra megapotamica (Nect mega) Parapiptadenia rígida (Para rig), Sebastiania brasiliensis (Seb bras), Allophylus edulis (Allo ed) Luehea divaricata (Lueh diva), Casearia sylvestris (Case sylv), Matayba elaeagnoides (Matay ela), Nectandra lanceolata (Nect lanc) e Cupania vernalis (Cupa ver), com suas respectivas abreviações utilizadas na figura 1(B). Destas, apenas oito apresentaram correlação com pelo menos uma variável ambiental significativa pelo coeficiente de Spearman, conforme tabela 1.

Na correlação das espécies pela CCA, (Figura 1) a espécie Trichillia claussenii destacou-se por sua alta dominância ecológica e alta correlação com terrenos de maior declividade em solos Litólicos rasos (eixo 1), onde observa-se a presença de afloramentos rochosos no início das encostas (Neossolos Litólicos 2, face A). Essa correlação também foi constatada por KLEIN (1984), por meio de observações ecológicas, LONGHI et al. (1986), por meio de análise quantitativa, no morro Botucaraí, e por SCIPIONI (2008), para a regeneração da espécie na mesma área. Segundo KLEIN (1984), a espécie é abundante não somente nas planícies aluviais, mas, principalmente, no alto das encostas sobre solos rochosos. Apesar de a espécie 
estar distribuída em todo gradiente, pode-se concluir, por meio da CCA, que essa espécie está altamente correlacionada com esse tipo de ambiente na floresta em sucessão avançada.

Porém, a CCA sugere que as espécies como: Myrcianthes pungens, Lonchocarpus sp., Parapiptadenia rigida, Cordia americana e Banara tomentosa estão ordenadas nos locais com maior relação $\mathrm{Ca} / \mathrm{Mg}$ e maior disponibilidade de cátions, em posições inferiores e intermediárias do terreno, com diferentes níveis de declividade (Neossolos Litólicos 1 e Neossolos Regolítico). Nas partes inferiores do terreno próximo aos cursos de água, a CCA indica maior abundância das seguintes espécies: Sebastiania commersoniana, Sebastiania brasiliensis e Allophylus edulis; por outro lado, Nectandra Ianceolata e Casearia sylvestris apresentaram sua abundância ligada aos Neossolos Litólicos 2 (face B) no topo do relevo, com baixa declividade. As demais espécies (Nectandra megapotamica, Cupania vernalis e Luehea divaricata) ocorreram em condições intermediárias no gradiente.

As espécies Cupania vernalis e Nectandra Ianceolata apresentaram relação negativa com a declividade. Na tabela 1 podem ser observados os valores das correlações entre abundância dessas espécies, com as principais variáveis ambientais consideras no estudo. Entretanto, as espécies Nectandra megapotamica, Cupania vernalis e Luehea divaricata foram consideradas abundantes nas porções intermediárias do relevo, sendo consideradas como de ampla distribuição sem preferência por solos, com exceção dos hidromórficos. Essas observações também foram constatadas por outros autores, como REITZ (1980) e PEDRALLI (1987). Nas porções inferiores da encosta, em região próxima aos cursos de água, a abundância de Sebastiania commersoniana, Sebastiania brasiliensis e Allophylus edulis foi maior (Figura 1). Nesse ambiente, o solo é mais úmido, por causa da drenagem do terreno e proximidade dos cursos de água. Essas condições ambientais, preferenciais do comportamento ecológico dessas espécies, foram relatadas por alguns autores, priorizando ambientes úmidos e locais de luz difusa (REITZ, 1980; SMITH et al., 1988).

\section{CONCLUSÃO}

Nas áreas de encostas vulcânicas sem influência fluvial da Serra Geral analisadas neste trabalho, predominam uma única Ordem de solo, os Neossolos, característicos e dominantes dessa situação ambiental. Estes apresentaram pouca variação nas suas características morfológicas e químicas, não proporcionando condições ambientais distintas no substrato do gradiente topográfico da floresta para formar grupos florísticos ou locais com espécies arbóreas específicas, somente variando na abundância das espécies, com destaque para Trichillia claussenii, que apresentou maior densidade de indivíduos nas áreas de menor estabilidade de elevada declividade no cume da encosta.

\section{REFERÊNCIAS}

EMBRAPA. Manual de métodos de análises de solo. 2.ed. Rio de Janeiro: EMBRAPA, Centro Nacional de Pesquisa de Solos, 1997. 212p.

EMBRAPA. Sistema de classificação brasileiro de classificação de solos. 2.ed. Rio de Janeiro: EMBRAPA, Centro Nacional de Pesquisa de Solos, 2006. 306p.

HERRMANN, M.L. de P.; ROSA, R. de O. Relevo. In: MESQUITA, O.V. Geografia do Brasil. Rio de Janeiro: IBGE, 1990. V.2, p.61-62.

KLEIN, R.M. Meliáceas. In: REITZ, P.R. Flora ilustrada catarinense. Itajaí: Herbário Barbosa Rodrigues, 1984. N.1, p.20-28.

LIETZKE, D.A.; WEBER, R.S. The importance of Cr horizons in soil classification and interpretations. Soil Sci Soc Am J, v.45, p.593-599, 1981.

LONGHI, S.J. et al. Diferenciação dos tipos florestais do morro Botucaraí, em Candelária, Rio Grande do Sul. Acta For Bras, v.1, p.99-114, 1986.

MCCUNE, B.; MEFFORD, M.J. PC-ORD, version 5.0, Multivariate analysis of ecological data. MjM Solfware Desing, Glaneden Beach, 2006. 40p.

OLIVEIRA, M. de L.A.A. de. Dados florísticos preliminares e elaboração da flórula vascular da Reserva Biológica do IbicuíMirim, Santa Maria, Rio Grande do Sul, Brasil. Iheringia, Sér Bot, v.41, p.141-153, 1991.

OLIVEIRA, M. de L.A.A. de et al. Levantamento florístico de fragmentos florestais na bacia hidrográfica do rio Gravataí, Rio Grande do Sul, Brasil. Iheringia, Sér Bot, v.60, n.2, p.269284, 2005.

OLIVEIRA-FILHO, A.T. et al. Variações estruturais do compartimento arbóreo de uma floresta semidecídua altomontana na chapada das Perdizes, Carrancas, MG. Rev. bras. Bot., v.27, n.2, p.291-309, 2004. Disponível em: http:// www.scielo.br /scielo.php?script=sci_issuetoc \&pid=0100840420040002\&lng=en\&nrm=iso. Acesso em: 15 nov. 2008. doi: 10.1590/S0100-84042004000200009.

OLIVEIRA-FILHO, A.T. et al. Floristic relationships of seasonally dry forests of eastern South America based on tree species distribution patterns. In: PENNINGTON, R.T. et al. Neotropical savannas and dry forests: plant diversity, biogeography and conservation. Boca Raton: CRC, 2006. p.159-192. 
PEDRALLI, G. Lauráceaes. In: REITZ, P.R. Flora ilustrada catarinense. Itajaí: Herbário Barbosa Rodrigues, 1987. N.1, p.62-79.

PEDRON, F. de A. Mineralogia, morfologia e classificação de Neossolos e saprolitos derivados de rochas vulcânicas no Rio Grande do Sul. 2007. 160f. Tese (Doutorado em Ciência do Solo) - Curso de Pós-graduação em Ciência do Solo, Universidade Federal de Santa Maria, RS.

PEDRON, F. de A. et al. Morfologia e classificação taxonômica de neossolos e saprolitos derivados de rochas vulcânicas da Formação Serra Geral no Rio Grande no Sul. Rev Bras Ciênc Solo [online], v.33, n.1, p.119-128, 2009. Disponível em: <http: //www.scielo.br/scielo.php?script=sci_pdf\&pid=S010006832009000100013\&lng=en\&nrm $=$ iso\&tlng=pt $>$ Acesso em: 28 abr. 2010. doi: 10.1590/S0100-06832009000100013.

REITZ, R. Sapindáceas. In: REITZ, P.R. Flora ilustrada catarinense. Itajaí: Herbário Barbosa Rodrigues, 1980. N.1, p.123-129.

SANTOS, R.D. et al. Manual de descrição e coleta de solo no campo. 5. ed. Viçosa: SBCS, 2005. 100p.

SCIPIONI, M.C. Análise dos padrões florísticos e estruturais da comunidade arbórea-arbustiva e da regeneração natural em gradientes ambientais na floresta estacional, RS, Brasil. 2008. 89f. Dissertação
(Mestrado em Engenharia Florestal) - Programa de Pósgraduação em Engenharia Florestal, Universidade Federal de Santa Maria, RS.

SCHAFER, W.M. et al. Morphology of a paralithic contact in a soil over soft sandstone. Soil Sci Soc Am J, v.43, p.383386, 1979.

SMITH, L.B et al. Euforbiáceas. In: REITZ, P.R. Flora ilustrada catarinense. Itajaí: Herbário Barbosa Rodrigues, 1988. N.1, p.308-316.

SOUZA, J.S. et al. Análise das variações florísticas e estruturais da comunidade arbórea de um fragmento de floresta semidecídua às margens do rio Capivari, Lavras, MG. Rev Árvore, v.27, n.2, p.185-206, 2003. Disponível em: <http://www.scielo.br/scielo.php ? s c r i p t $=$ s c i $-p$ d f \& p i d $=$ S 01100 $67622003000200009 \& \operatorname{lng}=\overline{\mathrm{en}} \& \mathrm{nrm}=\mathrm{iso} \& \mathrm{t} \operatorname{lng}=\mathrm{pt}>$. Acesso em: 15 jan. 2010. doi: 10.1590/S0100-67622003000200009.

STRECK, E.V.et al. Solos do Rio Grande do Sul. Porto Alegre: UFRGS, 2002. 107p.

TER BRAAK, C.J.F. The analysis of vegetation-environment relationship by canonical correspondence analysis. Vegetatio, n.69, p.69-77, 1987.

TER BRAAK, C.J.F. Ordination. In: JONGMAN et al. Data analysis in community and landscape ecology. 2.ed Cambridge: Cambridge Univ, 1995. Cap.5, p.91-173. 